\title{
Unusual presentation of residual subretinal fluid composition after surgery for acute rhegmatogenous retinal detachment
}

This article was published in the following Dove Press journal:

Clinical Ophthalmology

4 June 2013

Number of times this article has been viewed

\author{
Saba Al Rashaed \\ Vitreoretinal Division, King Khaled \\ Eye Specialist Hospital, Riyadh, \\ Saudi Arabia
}

\begin{abstract}
The purpose of this paper is to report an unusual case of accumulation of residual subretinal fluid after surgery for acute rhegmatogenous retinal detachment, sparing the fovea. A 28-year-old male presented with a four-day history of acute visual loss in his right eye secondary to bulbous rhegmatogenous retinal detachment, sparing the fovea. The patient underwent an uneventful pars plana vitrectomy and scleral buckling procedure. At four weeks postoperatively (after complete gas resorption), the visual acuity was 20/40. However, the patient complained of blurred vision. A dilated fundus examination showed a flat retina and the presence of multiple yellowish subretinal deposits resembling vitelliform lesions in the macula. Some lesions were encroaching on the fovea, and were connected via a tract to a previous horseshoe tear with evidence of a thin layer of subretinal fluid. The patient symptoms persisted for one year postoperatively. However, the retina remained flat with evidence of retinal pigment epithelium mottling and faint scars corresponding to previous lesions. Persistent subretinal fluid with thick subretinal precipitate can occur even after successful surgery for acute retinal detachment sparing the fovea and cause visual dysfunction.
\end{abstract}

Keywords: rhegmatogenous retinal detachment, subretinal fluid composition, persistent subretinal fluid, visual dysfunction

\section{Background}

Shallow subretinal fluid may persist after rhegmatogenous retinal detachment surgery, even though the retina may appear fully attached on ophthalmoscopy. Robertson ${ }^{1}$ described subretinal precipitates after delayed absorption of shallow subretinal fluid following scleral buckling procedures. Recently, optical coherence tomography (OCT) has been used to document persistent subretinal fluid after rhegmatogenous retinal detachment surgery. OCT images show shallow remnants of subretinal fluid despite resolution of all retinal breaks and a fully attached retina on ophthalmoscopy. ${ }^{2}$ In a recent study, Ricker et $\mathrm{al}^{3}$ found persistent subretinal fluid in $94 \%$ of cases at one month postoperatively. Persistent subretinal fluid may decrease visual recovery, causing poor central vision, metamorphopsia, and loss of depth perception. However, the effect on the final outcome remains unclear. ${ }^{2-5}$ There are several possible causes for persistent subretinal fluid, but there is little conclusive evidence for either vitrectomy versus buckling surgery, cryotherapy, use of tamponade, or complete drainage of subretinal fluid. Studies of various case series using immunohistochemistry and electron microscopy show increased cellularity in the photoreceptor outer segment (fragments) in the shallow subretinal fluid from patients with longstanding rhegmatogenous retinal detachment and persistent subretinal fluid on OCT postoperatively. Here we present
Vitreoretinal Division, King Khaled Eye Specialist Hospital, PO Box 7I9I, Riyadh I 1462, Kingdom of Saudi Arabia Email srashaed@kkesh.med.sa 
a case of accumulation of thick residual shallow subretinal fluid, after retinal surgery for acute rhegmatogenous retinal detachment, sparing the fovea.

\section{Case report}

A 28-year-old male presented with acute visual loss in the right eye of four days' duration. The patient had undergone bilateral laser in situ keratomileusis for myopia (-6 D) 11 months prior to presentation. Clinical examination revealed that visual acuity was 20/40 OD and fundus examination showed an acute bulbous rhegmatogenous retinal detachment sparing the fovea that was caused by a large horseshoe tear located in the supratemporal quadrant of the fundus at the equator. The patient underwent an uneventful 20 gauge pars plana vitrectomy with perfluoropropane/air exchange (15\% perfluoropropane gas injection), endolaser for the causative break, and an encircling silicone band scleral buckle (size 240). The patient was asked to remain recumbent on his left side for two weeks postoperatively.

A detailed fundus examination was obtained four weeks postoperatively when the gas had completely resolved; visual acuity at this time was $20 / 40$, but the patient complained of blurry vision. On fundus examination, the retina was flat with multiple yellowish subretinal deposits resembling vitelliform lesions in the macula and outside the retinal arcade. Some of the lesions were encroaching the fovea and were connected by a tract to the area of the previous horseshoe tear, with evidence of a shallow layer of thick, yellowish subretinal fluid (Figure 1). OCT showed shallow subretinal fluid with hyper-reflective material corresponding

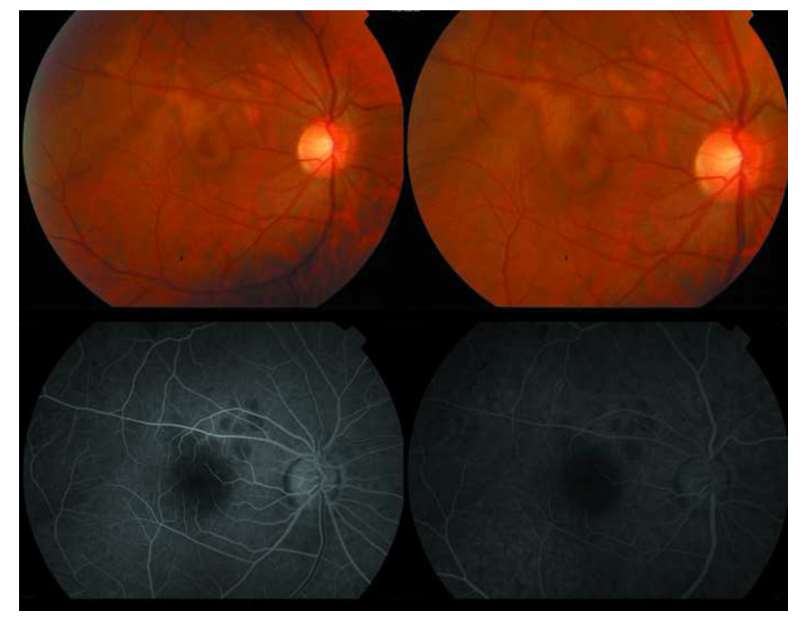

Figure I Yellowish subretinal deposit resembling vitelliform lesions in the macula and outside the retinal arcade encroaching onto the fovea. Some of these lesions were connected by a tract to the area of previous horseshoe tears. Fluorescein angiography demonstrated blockage of dye, corresponding to residual subretinal fluid accumulation. to the pseudovitelliform lesions sequestered between the retinal pigment epithelium and neurosensory layer (Figure 2). However, fluorescein angiography demonstrated blockage of the dye. We consider that this corresponded to a residual subretinal fluid precipitate. The patient was followed up frequently over one year postoperatively and his symptoms persist to date, with visual acuity remaining at 20/40. Fundus examination consistently showed a flat retina with retinal pigment epithelium mottling, and faint scars corresponding to previous lesions (Figure 3). OCT showed complete resolution of shallow subretinal fluid, and the subretinal deposit (Figure 4). Fluorescein angiography showed a window defect and late staining, corresponding to the area of retinal pigment epithelium mottling, with faint scarring.

\section{Discussion}

The pathophysiology of persistent subretinal fluid remains poorly understood. Both research ${ }^{5,6}$ and clinical practice demonstrate that fluid absorption is favored by strong forces, including oncotic pressure gradients, hydrostatic pressure, and an active retinal pigment epithelial pump. In many cases of rhegmatogenous retinal detachment, fluid absorption proceeds very rapidly when the retinal breaks are closed, even without drainage of fluid, as in pneumatic retinopexy. However, it is still unclear why small fluid remnants take months to resorb in certain cases. In new detachments, an oncotic pressure gradient and an active retinal pigment epithelial pump favor rapid fluid absorption when all retinal breaks are closed. ${ }^{7}$ Negi and Marmor $^{6}$ demonstrated that breakdown of the blood-retinal barrier, caused by damage to the retinal pigment epithelium, facilitates absorption of the shallow subretinal fluid due to the greater oncotic pressure in the choroid. However, the pathophysiology of longstanding detachments is different. Nonsyneretic vitreous may slow the progression of retinal detachment by tamponading retinal

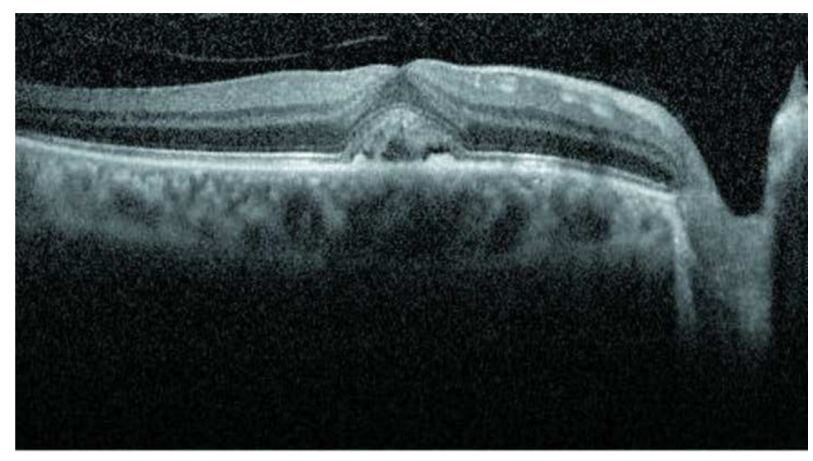

Figure 2 Optical coherence tomography showing the presence of subretinal fluid with hyper-reflective material corresponding to pseudovetilliform lesions sequestered between the retinal pigment epithelium and neurosensory layer. 


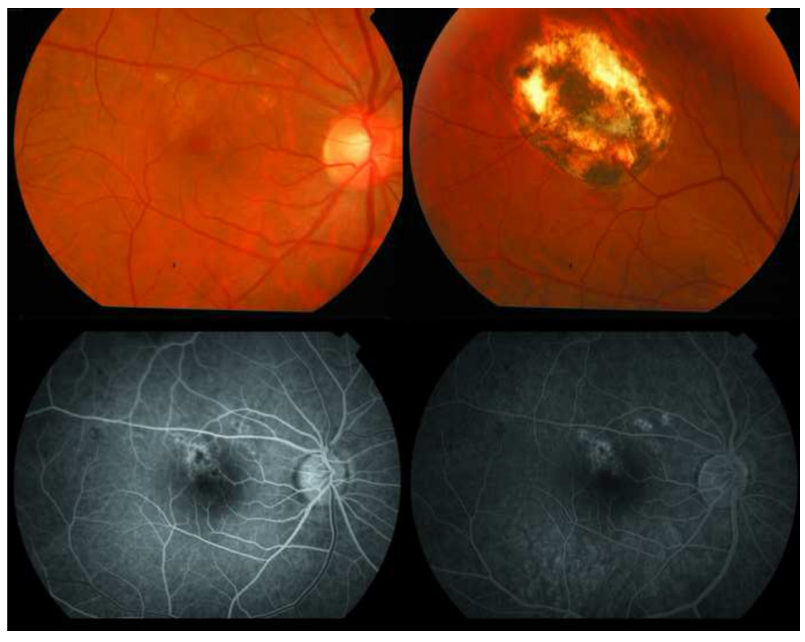

Figure 3 Fundus examination showed a flat retina and retinal pigment epithelium mottling with faint scars corresponding to previous lesions. Fluorescein angiography showed a window defect and late staining corresponding to the retinal pigment epithelium mottling with faint scars.

breaks, and may be an important factor in the persistence of shallow subretinal fluid after retinal reattachment.

The high viscosity of shallow subretinal fluid may cause it to stick to the retinal pigment epithelium when it is drained. Also, higher hyaluronic acid levels in the vitreous, and consequently in the shallow subretinal fluid, would slow fluid absorption. It is well known that hyaluronic acid is the preferred substance for experimental retinal detachment, because it maintains the detachment over long periods of time, possibly by inhibiting phagocytic activity in the retinal pigment epithelium. ${ }^{8}$ Further, in longstanding detachments, the higher oncotic pressure of the fluid remnants may act against fluid absorption. The oncotic pressure of the shallow subretinal fluid increases with duration of detachment. ${ }^{9}$ Although the majority of studies do report that persistent fluid may slow visual recovery, with resolution of fluid usually

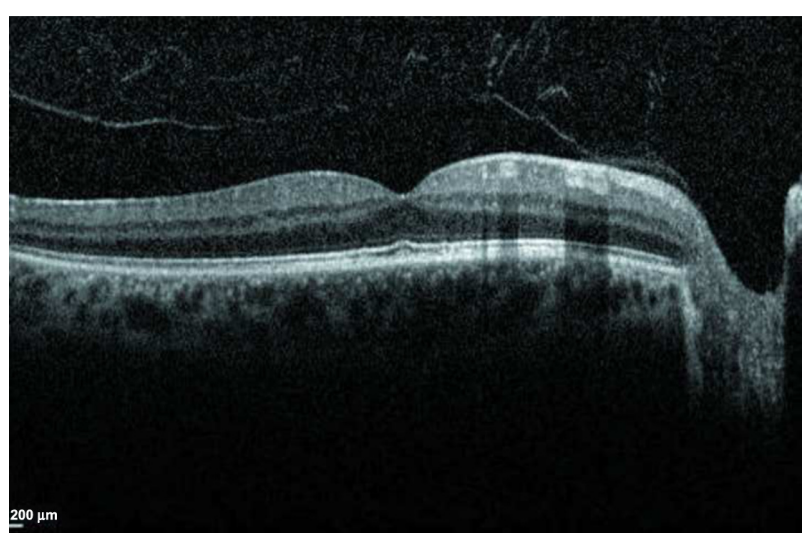

Figure 4 Optical coherence tomography showing complete resolution of subretinal fluid and disappearance of the subretinal deposits. coinciding with improved visual acuity, the final outcome may not be affected. ${ }^{2-5}$ However, patients suffering from persistent foveal detachment may have significant complaints about poor central vision. Metamorphopsia and loss of depth perception can persist for over a year after "successful" retinal detachment surgery, and further damage to the retinal pigment epithelium is quite possible when fluid persists under the macula. In experimental detachments using hyaluronic acid, photoreceptor apoptosis is observed within weeks. ${ }^{10}$ Irreversible retinal pigment epithelium damage could occur sooner in cases of persistent shallow subretinal fluid after retinal detachment.

Our case had a very recent rhegmatogenous retinal detachment and there were no signs that it was chronic, such as subretinal precipitate. It is possible that residual shallow subretinal fluid was responsible for formation of the subretinal vitelliform material, because we drained the shallow subretinal fluid through the original break, and it is quite likely that some shallow subretinal fluid remained trapped between the break and the posterior pole at the end of the gas/air exchange procedure. Presumably, the shallow subretinal fluid was more conspicuous in this patient with bullous rhegmatogenous retinal detachment. Subsequently, the patient developed a residual thick subretinal deposit after absorption of the shallow subretinal fluid, which was demonstrated clinically, as well as on OCT and fluorescein angiography. This material was most likely lipofuscin, generated from damage to the outer segments of the photoreceptors, and as these materials faded, they resulted in retinal pigment epithelium mottling with faint scarring. We believe that this is a rare presentation with unusual sequelae after management of acute rhegmatogenous retinal detachment. Persistent subretinal fluid with thick composition does occur even after successful surgery for acute retinal detachment sparing the fovea and can cause visual dysfunction.

\section{Disclosure}

The author has no proprietary interest in the material presented in this case report.

\section{References}

1. Robertson DM. Delayed absorption of subretinal fluid after scleral buckling procedures: the significance of subretinal precipitates. Trans Am Ophthalmol Soc. 1978;3:1311-1316.

2. Baba T, Hirose A, Moriyama M, Mochizuki M. Tomographic image and visual recovery of acute macula-off rhegmatogenous retinal detachments. Graefes Arch Clin Exp Ophthalmol. 2004;242:576-581.

3. Ricker LJ, Noordzij LJ, Goezinne F, et al. Persistent subfoveal fluid and increased reoperative foveal thickness impair visual outcome after macula-off retinal detachment repair. Retina. 2011;31:1505-1512. 
4. Benson SE, Schlottmann PG, Bunce C, et al. Optical coherence tomography analysis of the macula after scleral buckling surgery for retinal detachments. Ophthalmology. 2007;114:108-112.

5. Veckeneer M, Derycke L, Lindstedt EW, et al. Persistent subretinal fluid after surgery for rhegmatogenous retinal detachment: hypothesis and review. Graefes Arch Clin Exp Ophthalmol. 2012;250:795-802.

6. Negi A, Marmor MF. The resorption of subretinal fluid after diffuse damage to the retinal pigment epithelium. Invest Ophthalmol Vis Sci. 1983;24:1475-1479.

7. Tsuboi S, Pederson JE. Volume flow across the isolated retinal pigment epithelium of cynomologus monkey eyes. Invest Ophthalmol Vis Sci. 1988;29:1652-1655.
8. Zacks DN, Han Y, Zeng Y, et al. Activation of signaling pathways and stress-response genes in an experimental model of retinal detachment. Invest Ophthalmol Vis Sci. 2006;47:1691-1695.

9. Takeuchi A, Kricorian G, Marmor MF. When vitreous enters the subretinal space. implications for subretinal fluid protein. Retina. 1996;1: 426-430.

10. Anderson DH, Stern WH, Fisher SK, et al. Retinal detachment in the cat: the pigment epithelial-photoreceptor interface. Invest Ophthalmol Vis Sci. 1983;24:906-926.
Clinical Ophthalmology

\section{Publish your work in this journal}

Clinical Ophthalmology is an international, peer-reviewed journal covering all subspecialties within ophthalmology. Key topics include: Optometry; Visual science; Pharmacology and drug therapy in eye diseases; Basic Sciences; Primary and Secondary eye care; Patient Safety and Quality of Care Improvements. This journal is indexed on Submit your manuscript here: http://www.dovepress.com/clinical-ophthalmology-journal

\section{Dovepress}

PubMed Central and CAS, and is the official journal of The Society of Clinical Ophthalmology (SCO). The manuscript management system is completely online and includes a very quick and fair peer-review system, which is all easy to use. Visit http://www.dovepress.com/ testimonials.php to read real quotes from published authors. 